\title{
Incorporating Critical Thinking into an Engineering Undergraduate Learning Environment
}

\author{
Desmond Adair $^{1} \&$ Martin Jaeger ${ }^{2}$ \\ ${ }^{1}$ School of Engineering, Nazarbayev Universiy, Astana, Republic of Kazakhstan \\ ${ }^{2}$ School of Engineering, University of Tasmania, Tasmania, Australia \\ Correspondence: Desmond Adair, School of Engineering, Nazarbayev University, 010000, Republic of Kazakhstan. \\ Tel: 7-7172-706-531.
}

Received: November 12, 2015

Accepted: January 25, 2016

Online Published: January 28, 2016

doi:10.5430/ijhe.v5n2p23

URL: http://dx.doi.org/10.5430/ijhe.v5n2p23

\begin{abstract}
Critical thinking extends to all aspects of professional engineering, especially in technical development, and, since the introduction of the ABET 2000 criteria, there has been an increased emphasis in engineering education on the development of critical thinking skills. What is hoped for is that the students obtain critical thinking skills to complement their abundant logical thinking skills. Critical thinking is a developmental skill that cannot be taught simply by traditional methods, i.e., step-by-step instruction followed by repetitive skills, as used for logical thinking skills. The research and development reported here is concerned with outlining how students first can be alerted to what critical thinking is, and how critical thinking can be nurtured through practical experience with appropriate guidance and reinforcement. The module 'Introduction to Fluid Mechanics' has been selected to demonstrate how formal critical thinking components may be introduced with the development of principles of logic and an obligatory problem solving procedure. A method of assessment during various phases of critical thinking, i.e., initial design or set-up, testing of method or prototype, and evaluation of the results, of open-ended assignments in engineering for each year of the undergraduate course has been developed.
\end{abstract}

Keywords: Critical thinking, Undergraduate, Learning environment, Assessment

\section{Introduction}

The quality of students' and engineers' thinking, and how they think, determines the quality of what they design, produce or make. Critical thinking, it is claimed, in engineering education occurs today mostly in a focused context, directed toward fulfilling one of several ABET learning outcomes (Claris \& Riley, 2013). Of course the teaching of critical thinking should be more than this, as critical thinking entails much more than the conventional practices in engineering, by considering and articulating assumptions in problem solving, selecting appropriate hypotheses and methods for experiments and structuring open-ended design problems. Just as is found in many professions, engineers now need, more than ever, strong critical thinking skills to deal with a world of increasingly rapid change and complexity. Much has been written in the literature in the contexts of problem solving (Lombard, 2004; Mina $e t$ al., 2003; Papadopoulos et al., 2006), conducting experiments (Bruno \& Anderson, 2005; Miller \& Olds, 1994) and open-ended design (Gurmen et al., 2003; Lunt \& Helps, 2001). Attention has also be given to critical thinking within topics in engineering such as ethical decision making (Swailie \& Kreppel, 2001; Wolverton \& Wolverton, 2003), social impacts of technology (Nelson, 2001), and positioning students and engineers from a stance of social justice (Baillie, 2013).

This work is concerned with examining what it means to teach critical thinking, and, how this can be achieved effectively. There is a definite need to help students develop higher-order thinking skills, i.e., to do something more sophisticated than recite back facts they have memorized from lectures or textbooks, sometimes with little required analysis (Bissell \& Lemons, 2006). What is hoped for as the outcome to this work is a major change in how students respond to problems and to give them the tools to think critically. Justification for the inclusion of critical thinking in the curriculum is well supported in the literature and by many national commissions (American Association for the Advancement of Science, 1989; Felder, 1987; National Academy of Sciences, 2003; Yuretich, 2004). Yet when trying to implement critical thinking as an explicit goal in undergraduate engineering, there does not seem to be a 
well-defined scheme to ensure success. This may be in part, due to a lack of a good method to assess improvement in critical thinking (Bissell \& Lemons, 2006).

It has been concluded that most students already consider themselves as effective critical thinkers, and faculty claim that critical thinking is a primary objective of their course, which may or may not be self-delusion (Paul et al., 1997). Also, it has been quickly recognized that although workshops and seminars on critical thinking have their place to initiate awareness, a systematic semi-implicit approach over a period of time is very necessary to cultivate critical thinking (Felder, 1984). That is, once the principles of critical thinking are grasped and, importantly accepted by the student, then a period of time is necessary for cultivation, practice and hopefully becoming second nature.

To improve, or even to initiate critical thinking, a model first needs to be developed, capable of analyzing and evaluating the way engineers think, and hence this model applied appropriately. The general consensus found in the literature is that an explicit initial course on developing critical thinking skills is needed followed by reinforcement (Niewoehner, 2006; O'Shea et al., 2012). It is this type of approach which is developed here, where the critical thinking course is followed by a preliminary initiative to cultivate more and systematic critical thinking within various engineering modules found in an undergraduate engineering course. There is also some attempt to assess any improvement in the students' ability to think critically.

In the rest of this paper, a discussion will be given of critical thinking in general, comments on developing an initial course on critical thinking, and how critical thinking may be reinforced throughout the rest of an undergraduate engineering course. An assessment method of student critical thinking development as they progress through their undergraduate engineering course is included. A section is also included summarizing the results of a discussion on how students view critical thinking in relation to themselves and how necessary they feel critical thinking is. Results of an experiment using a pre- and post-test control group design to analyse the effect of the inclusion of critical thinking components in the undergraduate module 'Introduction to Fluid Mechanics' are reported.

\section{Initial Thoughts on Critical Thinking}

To solve tough problems of society, especially when they are technological, creative engineers are needed (Felder, 1987). It would seem that the responsibility of schools of engineering in universities, and also in society's best interest would be to create creative engineers. Part of the problem of not dealing with critical thinking at undergraduate level is a tendency to push more and more information into each module so that just covering the syllabus material is all there is time for. Also faculty do not get personally rewarded for innovative teaching at the same level as research (Felder, 1984) so providing little incentive other than personal satisfaction. While there are many innovative ideas and trends within today's teaching (Adair et al., 2014; Felder et al., 2000; Adair \& Jaeger, 2013; Seymour, 2002), there is still the tendency to over-use the lecture-homework-quiz format. This is indeed an efficient method of delivering knowledge and skills, but it has never been shown to be effective at producing the critical, innovative thinking skills needed to solve difficult technological problems. For critical thinking to be included in a meaningful way within engineering education undergraduate teaching and learning, it is argued that the following premises could give a basis for development:

- Defining what 'critical thinking' actually means and entails.

- Certain techniques have been identified by education theorists and psychologists, which have the possibility of stimulating creativity if integrated properly into the more traditional forms of instruction.

- While it is recognized that an initial course may be desirable/needed on critical thinking, the techniques mentioned above must be introduced throughout the curriculum.

- The methods intended to develop creative/high-level thinking must not take up too much time. As much integration as possible, with the existing syllabus, is desirable.

- Establishing a method to assess, however crudely, to measure 'critical thinking ability'.

- Faculty should form workshops to discuss the sharing/development of techniques designed to encourage critical thinking.

An integral part of teaching and learning is the ability to be able to assess its effectiveness. When it comes to assessing critical thinking, many faculty in fact have expressed the view that critical thinking cannot be achieved or, there is no current satisfactory method for assessment (Beyer, 1984; Cromwell, 1992; Aviles, 1999). However, there is also evidence from a large body of literature showing critical thinking can indeed be assessed, although careful selection of the assessment method may be warranted (Cromwell, 1992; Fisher, 1997) although most of this assessing is subject-independent, i.e. the measurement of critical thinking ability has no regard for the context. Such 
testing may have problems, including: the measurements may not indicate anything useful about discipline-specific knowledge; administering such tests takes time away from the course (can be viewed as wasted time); faculty lack time to really get to understand the structure and theory behind the tests (Bissell \& Lemons, 2006). Rather, it is thought preferable to develop assessment methodology which includes both content and cognitive skills testing, and, in which the critical-thinking component can be explicitly identified and then scored.

\section{Designing a Critical Thinking Model}

Building on the premises listed in the last section, a summary of the research is now given which contributed to a course on critical thinking plus a strategy to implement critical thinking throughout an engineering undergraduate course.

\subsection{What is Critical Thinking}

Different definitions of the term 'critical thinking' abound in the literature (Brookfield, 2012; Facione, 2015; O'Shea et al., 2012; Aretz et al., 1997) and this variability may in fact impede progress on all fronts (Resnick, 1987). Most of the definitions share some basic features and probably address some aspect of critical thinking (Potts, 1994). In the face of so many definitions, some authors go for a 'consensus definition' and others go for one that meets their needs and consistency in applying it (Bissell \& Lemons, 2006). For example, Baillie (2012) explains critical thinking from the point of view of outcomes and at the beginning of her course she explains "students will be able to demonstrate an ability to think critically and reflexively not only about engineering practices in the abstract but about their own work in this unit; assess and apply different views of the relationship between science, technology and society; consider rights, justice, freedom and ethics and illustrate their relation to engineering practice; and compare and critique local and global technological practices". It can be taken from this lengthy definition that critical thinking goes beyond thinking clearly or logically and actually looks in depth at various relevant concepts by exploring such things as underlying issues, loosely connected issues or seemingly unconnected issues.

However, important to critical thinking is how to assess it. With this in mind, a definition, and the working one for this paper, based on Bloom's taxonomy of educational objectives (Bloom, 1956), was chosen. Bloom's taxonomy delineates six categories of learning basic knowledge, secondary comprehension, application, analysis, synthesis and evaluation, where the first two categories do not require critical thinking, but the last four all require higher-order thinking which characterizes critical thought. Breaking down academic skills in this way and to some extent identifying critical thinking provides a reasonable breakdown for designing specific assessment designs. The assessments developed however cannot be used to measure critical thinking independent of content (Bissell \& Lemons, 2006).

\subsection{Initial Critical Thinking Course}

An initial course to introduce students to ideas which should improve their thought was devised. The course is based on Paul's critical thinking model (Paul \& Elder, 2002). The model, shown on Figure 1, has the goal of producing a mature engineering thinker.

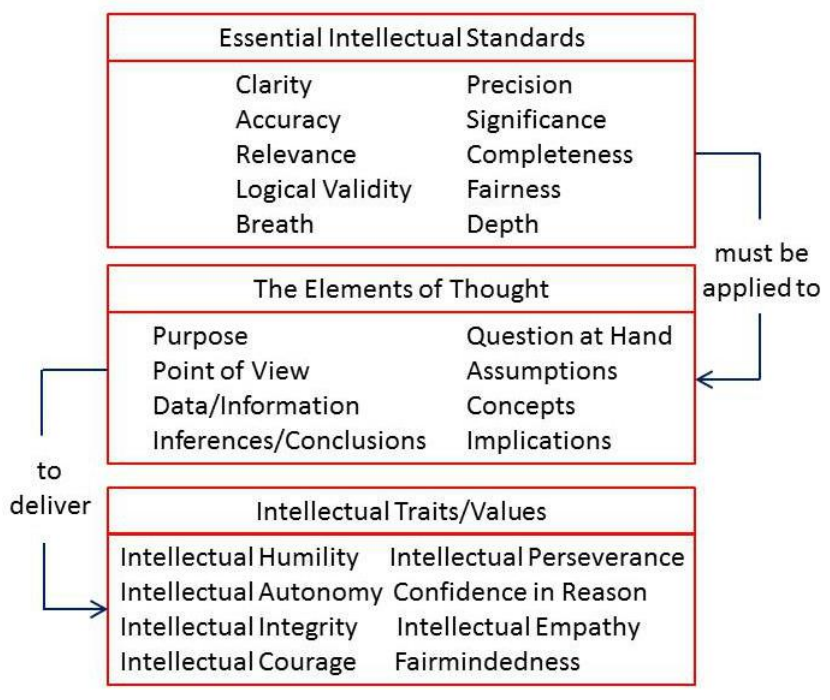

Figure 1. Paul's critical thinking model (Paul \& Elder, 2002) 
The critical thinking course lasted one semester in the engineering undergraduate degree preparatory year (Level 0) and consisted of lectures, group discussions, and practicing analyses. Engineering design was used as the vehicle to introduce elements of critical thinking.

The course actually starts with the third grouping, i.e. lecturing on discussing 'Intellectual Traits/Values' in relation to engineering practice, followed by an introduction to 'The Elements of Thought', where students start analysing how they think and how others think. Lastly the 'Essential Intellectual Standards' are lectured on, discussed and practiced using exercises based on engineering design. Each of these sections is now briefly discussed.

\subsubsection{Intellectual Traits/Values}

The overall objective here is to make students aware that professional engineers must cultivate personal and intellectual values, so that they think with insight and integrity (Paul \& Elder, 2002). For engineers certain distinct issues come to the fore within each category: Intellectual humility admits to ignorance and being truthfully sensitive to what you know and what you do not know. Intellectual autonomy is the ability to think for oneself while adhering to standards of rationality which is important so as not to accept other viewpoints without questioning. Intellectual integrity means that you do not have double standards and you hold yourself to high intellectual standards expected by you in others. Intellectual courage is when you have strong views, which may be unpopular, and you are willing to express these views to your peers. Intellectual perseverance is the ability to work through complex and frustrating tasks. Confidence in reason is a mixture of being open-minded regarding other peoples' views, encouragement of other people to have a view and the ability not to distort views to support my own position. Intellectual empathy is important as it helps the engineer grow and mature as he/she takes on different views. Fair-mindedness is the ability to treat all viewpoints without bias or prejudice and so be able to make judgments appropriately. The method of delivering this part of the course was to first give an introductory lecture followed by small group discussions using appropriate lists of questions. At the end of each session, the complete cohort came together to summarise the findings.

\subsubsection{The Elements of Thought}

In this section of the course the aim was to help students evaluate how they think, or how others think (Paul \& Elder, 2002). The reasoning behind the structure of this part of the course is that whenever we think, we think for a purpose within a point of view, based on assumptions, leading to implications or consequences. We use data, facts and experiences, to make inferences and judgments, based on concepts and theories, to answer a question or solve a problem. A similar approach for delivery was used as for the first section of the course, where introductory lectures were given, followed by discussions and exercises based on engineering design.

\subsubsection{Essential Intellectual Standards}

Such standards need to be applied when one is interested in checking the quality of reasoning about an engineering problem or project (Paul \& Elder, 2002). To think professionally as an engineer means having command of all of these standards. As with the last section delivery here was by introductory lectures, followed by discussion and exercises based on engineering design. A brief list of typical questions associated with each of the intellectual standards is given in Table 1. 
Table 1. Typical design questions associated with intellectual standards (Paul \& Elder, 2002)

\begin{tabular}{|c|c|}
\hline Intellectual Standards & Design Questions \\
\hline \multirow[t]{2}{*}{ Clarity } & - What are the success criteria? \\
\hline & - Have assumptions been clearly defined? \\
\hline \multirow[t]{2}{*}{ Accuracy } & - Are the modelling assumptions appropriate? \\
\hline & - Has the test equipment been calibrated? \\
\hline \multirow[t]{2}{*}{ Relevance } & - Does the design address the requirements? \\
\hline & - Has irrelevant data been included? \\
\hline \multirow[t]{2}{*}{ Logical validity } & - Are design decisions based on appropriate analysis? \\
\hline & - Are there any hidden assumptions? \\
\hline \multirow[t]{2}{*}{ Breath } & - Have alternative approaches been considered? \\
\hline & - Have end-of-life issues been considered? \\
\hline \multirow[t]{2}{*}{ Precision } & - What are the accepted tolerances? \\
\hline & - What are the error bars or confidence bounds? \\
\hline \multirow[t]{2}{*}{ Significance } & - What are the design drivers? \\
\hline & - What impact will there be on the market? \\
\hline \multirow[t]{2}{*}{ Completeness } & - Is there room for further development? \\
\hline & - How could the next version be improved? \\
\hline \multirow[t]{2}{*}{ Fairness } & - Are vested interests influencing the design? \\
\hline & - Has public/community interests been considered? \\
\hline \multirow[t]{2}{*}{ Depth } & - How far have the complexities been accounted for? \\
\hline & - Has growth capability been addressed? \\
\hline
\end{tabular}

\subsection{Reinforcement Throughout the Undergraduate Course}

In addition to the 'Initial Critical Thinking Course', it is thought imperative to integrate critical thinking into each of the modules found in the engineering undergraduate course. The support of faculty members is indispensable here, as they have the power to include critical thinking or not in their modules. Seminars/discussions were held for the faculty on the inclusion of critical thinking in the classroom at the beginning of the academic year and several times during a semester derived from the theory put forward by Glaser (1941), who has suggested five components critical to the reinforcement of critical thinking.

- The first component, specific knowledge, was based on the belief that knowledge was necessary for critical thinking. Engineers must have a knowledge base on which to build their critical thinking skills.

- The second component is experience. Engineers have the know-how that allows for instantaneous recognition of patterns and intuitive responses in expert judgment.

- The third component is competencies. General critical thinking competences are related to the scientific process, hypothesis generation, problem solving, and decision-making.

- The fourth component is attitude, including confidence, independence, fairness, responsibility, risk taking, discipline, perseverance, creativity, curiosity, integrity, and humility; and intellectual standards, including clarity, precision, specificity, accuracy, relevance, plausibility, consistency, logicality, depth, broadness, competence, significance, adequacy, and fairness.

- Finally the fifth component is professional standards so as to accentuate safe, competent engineering practice.

Three levels of critical thinking were identified in the seminar. An initial level where answers to complex problems are right or wrong and there is only one right answer. A second level was the complex level where students could recognize options and alternatives, but did not make a commitment to any one solution. The final level, and ultimate 
goal, was commitment by the students to a solution. At this level, students (engineers) must be encouraged to choose an action or belief based on the options identified at the complex level.

The faculty were then encouraged to think about the following so as to facilitate better integration of critical thinking skills into their teaching and learning as outlined in Table 2 (Purves, 2009):

Table 2. Factors that influenced the development of critical thinking skills

\begin{tabular}{ll}
\hline Pedagogical Factors that Influence Critical Thinking Development \\
\hline Curriculum Design & - Acquiring foundational concepts \\
& - Progressing from simple to complex concepts \\
& - Applying learning in the laboratories/projects \\
Integrative Learning Activities & - Tests \\
& - Case studies \\
& - Simulations \\
\hline Personal Factors that Influence Critical Thinking Development \\
\hline Curiosity \\
Confidence \\
Perseverance \\
\hline Other Factors that Influence Critical Thinking Development \\
\hline Faculty support \\
Reinforcement, both in and out of the engineering programme
\end{tabular}

\subsection{Assessment of Critical Thinking}

Current best practices in critical thinking for engineering education have already been surveyed (Cooney, Alfrey \& Owens, 2008), where two major themes emerged: Open-ended problem-solving assignments with no clear-cut "right" answer or approach, and written assignments with a reflective component, frequently requiring judgment in the face of uncertainty. Problem solving (Cloete, 2001) and the components of a complete act of thought as proposed by Dewey (1910) have been compared by Cooney et al. (2008). Dewey's work forms the foundation for current literature on critical thinking.

It is not the case that good assessment should be just the addition of assignments that draw on critical skills only. Such subject-independent assessments of critical thinking have indeed been developed and used (Cromwell, 1992; Fisher \& Scriven, 1997), but acceptance that such testing is useful is questionable in that faculty can doubt that the measurements indicate anything useful about discipline-specific knowledge, administering such tests takes time away from the content of the course and can be costly, and, most faculty lack the time to learn the underlying structure and theory behind the tests (Bissel \& Lemons, 2006). With such practical problems, the assessment methodology developed here allows for discipline-specific, i.e., content-based questions within which the critical thinking component can be explicitly dissected and scored. The work is built on the work of others who have used Bloom's taxonomy to drive assessment decisions by using this taxonomy to explicitly define the skills that are required for each question.

\subsubsection{Designing Discipline-Specific Assessments of Critical Thinking}

The methodology consists of several steps in that questions which require both engineering knowledge and critical thinking skills are written followed by the documentation of the particular content and critical thinking skills required. A scoring rubric is then devised for the question. The scheme used here is built on the work of others (Porter, 2002, Middendorf \& Pace, 2004, Facione et al., 2000). The questions are reviewed by other faculty and the assessments are administered to the students and scored against a rubric that has been established in advance. It was found that rather than changing existing questions it was much more efficient to write new questions.

It was important to alert the students that expectations for the answers to these questions are different to what they may meet normally. The methodology has varying degrees of open-endedness in the answers while the questions are akin to more advanced questions found in engineering in that the students must analyse several concepts simultaneously to reach a reasonable answer. The students must be aware that a substantial part of the marks awarded are given to the rationale presented in the answers. The first step in evaluating the effectiveness of the problems is to clearly define the 
expectations for each question using the components of the framework of Ebert-May et al. (2003). These expectations are valid when the student gets the correct and complete answer, or when the student answers the question by drawing on the expected content. However, it is possible to apply the correct critical thinking skills to these problems while getting some aspects of the content wrong or employing an alternative body of content (Bissell \& Lemons, 2006). This is key to an assessment technique and a grading rubric (Bissell \& Lemons, 2006) was designed.

As with any short-answer examination, it is much easier to grade when students present clear answers combined with good reasoning. However, many students present answers which take a long time to decipher. Here, as the range of acceptable answers have been predefined through expectations, this problem is reduced.

\section{Including Critical Thinking Components in a Module}

There are many approaches to including critical thinking components in an engineering module (Mourtos et al., 2004), with the approach of Woods et al., 1997, chosen here as suitable for solving problems within the module 'Introduction to Fluid Mechanics'. Woods et al., 1997, state that for critical thinking and hence enhanced problem solving capabilities, students must have the attributes listed in Table 3. Here the affective levels are, receiving (a stimulus), responding (to a stimulus), valuing (an object or a behaviour), organisation (of values into a system) and characterisation (by a value complex). The cognitive levels are knowledge (recognise/recall information), comprehension (understand the meaning of information), application (use information appropriately to solve well-defined problems), analysis (deal with ambiguity with new ill-defined situations, formulate models), synthesis (combine elements in novel ways to generate new products or ideas) and evaluation (judge the worth of ideas, theories and opinions).

Table 3. Attributes needed for enhanced problem solving

\begin{tabular}{lll}
\hline & \multicolumn{1}{c}{ Attribute } & *Bloom's taxonomy \\
\hline 1. & Time is spent reading, gathering information and defining problems & Affective - level 2 \\
2. & Develop a process as well as having a few tactics and heuristics & Cognitive - level 4 \\
3. & Monitor any problem-solving process and reflect on its effectiveness & Cognitive - level 4 \\
4. & Emphasis accuracy as opposed to speed & Affective - level 3 \\
5. & Write down ideas and use charts/figures & Cognitive - level 3 \\
6. & Be organised and systematic & Affective - level 4 \\
7. & Be flexible and view the situation from different perspectives & Affective - level 4 \\
8. & Draw on pertinent subject knowledge and critically assess the quality, accuracy and & Cognitive - level 3 \\
& pertinence of that knowledge/data/results & \\
9. & Be willing to risk and cope with ambiguity, welcoming change and managing stress & Affective - level 4 \\
10. & Use an overall approach that emphasises fundamentals, rather than trying to combine & Cognitive - level 4 \\
& various memorised sample solutions & \\
\hline
\end{tabular}

*(Bloom, 1984; Bloom et al., 1984))

An approach traditionally used in many engineering curricula, i.e. teaching and learning heavily relying on exercise solving, where students develop solutions mainly based on solutions they have seen before, was taught to all students for approximately three quarters of the course. For the last quarter of the course the cohort was divided into two, with a control group continuing using the traditional approach, and, with an experimental group looking at problems with more critical thinking involved. This initial approach to including critical thinking in the module was to assess if any improvement was found in student results as discussed in subsection 5.1 below. In future it is intended to include critical thinking from the beginning of the module. The difference in the two types of course delivery during the last quarter of the module is summarized in Table 4. 
Table 4. Including critical thinking components verses the traditional exercise approach

\begin{tabular}{lll}
\hline \multicolumn{2}{c}{ Critical thinking delivery } & \multicolumn{1}{c}{ Exercise solving delivery } \\
\hline 1. & Emphasises best answer to an unknown & Emphasises only one right answer \\
2. & Include ambiguity within given information & Well defined situation with all information explicitly given \\
3. New situations given & Building on similar situations previously encountered \\
4. No clues as to what knowledge or skill needed & Hints and prescribed assumptions often given \\
5. & There could be more than one valid approach & One approach gives correct answer \\
6. & The method of solving is not clear & Build on familiar solutions \\
7. & Knowledge necessary to solve problem can & Problems tend to come from one subject only, and even only \\
& come from several subjects & one topic \\
8. & Required good communication skills & Communication skills not often required as equations/graphs
\end{tabular}

To give a framework to help the students be systematic in their approach to critical thinking, the method suggested by Woods, et al., 1997 was adopted. This is summarised in Table 5.

Table 5. Critical thinking methodology

\begin{tabular}{|c|c|c|}
\hline & Step & Description \\
\hline \multirow[t]{2}{*}{0.} & Motivation & I can do it \\
\hline & & I want to do it \\
\hline \multirow[t]{5}{*}{1.} & Definition of problem & Define what the problem states \\
\hline & & Sketch the problem \\
\hline & & Determine appropriate information \\
\hline & & Determine any constraints \\
\hline & & Define criteria for judging answer(s) \\
\hline \multirow[t]{4}{*}{2.} & Explore the problem & What is the real objective? \\
\hline & & What are the issues? \\
\hline & & What would be reasonable assumptions? \\
\hline & & Give an approximate answer \\
\hline \multirow[t]{4}{*}{3.} & Plan the solution & Develop overall plan \\
\hline & & Develop any sub-problems \\
\hline & & Select appropriate theory, principles and approach \\
\hline & & Determine any research that needs to be done \\
\hline 4. & Implement the plan & - \\
\hline \multirow[t]{2}{*}{5.} & Check the solution & Check accuracy of calculations \\
\hline & & Check units of calculated parameters \\
\hline \multirow[t]{4}{*}{6.} & Evaluate/reflect & Is the answer reasonable? Does it make sense? \\
\hline & & Were the assumptions good? \\
\hline & & $\begin{array}{l}\text { How does the solution compare with the approximate answer } \\
\text { of (2) above? }\end{array}$ \\
\hline & & When appropriate - is the solution ethically sound? \\
\hline
\end{tabular}

To assess the students' answers to questions, which included critical thinking, in the 'Introduction to Fluid Mechanics' module, a scoring rubric as shown in Table 6 was developed. What was looked for was a listing of given information, succinctly paraphrasing the problem statement, identifying assumptions, drawing a schematic, identifying the general 
governing equation(s), analysing the problem by simplification of the governing equations and performing necessary calculations, highlighting the results and drawing conclusions.

Table 6. Scoring rubric for questions involving critical thinking

\begin{tabular}{|c|c|c|c|c|}
\hline & 3 & 2 & 1 & 0 \\
\hline Givens & $\begin{array}{l}\text { All givens stated and } \\
\text { appropriately } \\
\text { selected; units given }\end{array}$ & $\begin{array}{l}\text { All givens stated but } \\
\text { not appropriately } \\
\text { selected; units given }\end{array}$ & $\begin{array}{l}\text { Given list not } \\
\text { complete }\end{array}$ & $\begin{array}{l}\text { Givens not explicitly } \\
\text { mentioned }\end{array}$ \\
\hline Problem statement & $\begin{array}{l}\text { Problem statement is } \\
\text { complete and clear }\end{array}$ & $\begin{array}{l}\text { Problem statement is } \\
\text { clear but missing } \\
\text { important facts }\end{array}$ & $\begin{array}{l}\text { Problem statement is } \\
\text { ambiguous }\end{array}$ & $\begin{array}{l}\text { Problem statement } \\
\text { missing }\end{array}$ \\
\hline Assumptions & $\begin{array}{l}\text { Assumption list is } \\
\text { complete }\end{array}$ & $\begin{array}{l}\text { Some assumptions } \\
\text { are missing or } \\
\text { confusing }\end{array}$ & $\begin{array}{l}\text { Most assumptions } \\
\text { are missing }\end{array}$ & $\begin{array}{l}\text { No assumptions } \\
\text { given }\end{array}$ \\
\hline Schematic & $\begin{array}{l}\text { Drawing is clear and } \\
\text { well labelled }\end{array}$ & $\begin{array}{l}\text { Drawing exists but } \\
\text { not clear }\end{array}$ & Ambiguities exist & $\begin{array}{l}\text { No relevant drawing } \\
\text { given }\end{array}$ \\
\hline Governing equation & $\begin{array}{l}\text { All relevant } \\
\text { governing equations } \\
\text { given }\end{array}$ & $\begin{array}{l}\text { Some key equations } \\
\text { missing or wrong }\end{array}$ & $\begin{array}{l}\text { Most key equations } \\
\text { are missing }\end{array}$ & $\begin{array}{l}\text { All given equations } \\
\text { are wrong }\end{array}$ \\
\hline Analysis & $\begin{array}{l}\text { Equations are } \\
\text { reduced according to } \\
\text { assumptions, and } \\
\text { algebraically } \\
\text { manipulated. Steps } \\
\text { are easy to follow. } \\
\text { Units dealt with } \\
\text { correctly }\end{array}$ & Some errors exist & Many errors exist & $\begin{array}{l}\text { Analysis is irrelevant } \\
\text { or unreadable }\end{array}$ \\
\hline Results & $\begin{array}{l}\text { Results are clearly } \\
\text { indicated, correct } \\
\text { and thorough }\end{array}$ & $\begin{array}{l}\text { Results given but not } \\
\text { clearly highlighted } \\
\text { or some results } \\
\text { missing }\end{array}$ & $\begin{array}{l}\text { Results are } \\
\text { incomplete or } \\
\text { difficult to identify }\end{array}$ & No results given \\
\hline Conclusions & $\begin{array}{l}\text { Correctness of the } \\
\text { results is judged. } \\
\text { Validity of answer in } \\
\text { terms of assumptions } \\
\text { is discussed }\end{array}$ & $\begin{array}{l}\text { Correctness of the } \\
\text { results is judged. } \\
\text { Validity of answer in } \\
\text { terms of assumptions } \\
\text { is discussed }\end{array}$ & $\begin{array}{l}\text { Wrong results are } \\
\text { improperly judged to } \\
\text { be reasonable, or } \\
\text { assumptions not } \\
\text { reflected on }\end{array}$ & $\begin{array}{l}\text { No conclusions are } \\
\text { drawn }\end{array}$ \\
\hline
\end{tabular}

\section{Feedback on the Critical Thinking Model}

The following section is divided into four sub-sections. The first subsection reports on an experiment using a pre- and post-test control group design (Pfahl et al., 2004). The next three each report feedback solicited using an online questionnaire, or, by group discussions with selected students and faculty concerning the critical thinking model implemented. The feedback is based on the first cohort using this critical thinking model.

\subsection{Evaluation of Including Critical Thinking Components in a Module}

An evaluation of including critical thinking components in the undergraduate module, 'Introduction to Fluid Mechanics' based on a controlled experiment (Pfahl et al., 2004) was carried out after the authors' ethics committee approved the study. The experiment used a pre- and post-test control group design. The students had to undertake two tests, one after about three-quarters of the teaching process had been given (pre-test) and one after the teaching process was fully complete (post-test). The experimental group were exposed to the critical thinking approach to solving problems during the last part of the course, whereas the control group was not. Learning effectiveness was evaluated by comparing within each group post- to pre-test scores and by comparing the scores between students of the experiment group and students of the experimental group and students of the control group to find relative and absolute learning effectiveness. 
In order to measure students' performance the students had to answer five open-ended questions with each question requiring careful critical analysis. The open-ended nature of questions was chosen in order to avoid mere guessing which usually takes place to an unidentifiable extent with multiple-choice tests. The teaching for the two groups (experiment - with critical thinking components - group A, control - without critical thinking components - group B) was delivered using traditional lectures, experiments and tutorials. The five test questions (scenarios) used in the experiment are listed in the Appendix.

The experimental hypotheses for the dependent variables were as follows:

1. Both groups (A: experimental group, B: control group) experience a positive learning effect and post-test scores are significantly higher than pre-test scores.

2. Group A experiences a higher relative learning effect than group B with regard to the improvement between preand post-test, and a higher absolute learning effect with regard to the post-test performance.

\subsubsection{Method}

For the experimental group A $(n=26)$ and group B $(n=25)$ of undergraduate students in their third semester were chosen. This was the first time in their engineering program they had met fluid mechanics as a topic and the groups were formed using the combined results of an earlier thermodynamics course so meeting the requirements for a quasi-experiment (Beins, 2009). Students who underwent the pre-test did not know that they would undergo a post-test after the teaching process and they were not allowed to keep the questions nor did they receive correct answers after the tests. The pre- and post-test procedures were introduced by explaining that the tests were not part of the formal assessment and that results would not influence their final grade.

The experimental hypotheses for the dependent variables were stated as follows:

1. Both groups (A: experimental group, B: control group) experience a positive learning effect and post-test scores are significantly higher than pre-test scores.

2. Group A experiences a higher relative learning effect than group B with regard to the improvement between pre-test and post-test, and a higher absolute learning effect with regard to the post-test performance.

In order to investigate the effect of the teaching effectiveness on the dependent variables Y.1 to Y.5 (see Appendix), standard significance testing was used. The null hypotheses were articulated as:

- $\quad H_{0,1}$ - there is no difference between pre- and post-test scores with group $\mathrm{A}$ and group $\mathrm{B}$.

- $H_{0,2 a}$ - there is no difference in relative learning effectiveness between group A and group B.

- $H_{0,2 b}$ - there is no difference in absolute learning effectiveness between group A and group B.

Following Pfahl et al. (2004), hypothesis $H_{0,1}$ was tested by applying a one-way paired $t$-test, whereas a one-sided $t$-test was the appropriate test for the independent samples of $H_{0,2 a}$ and $H_{0,2 b}$. A test to check the assumption of a normal distribution of the variables was conducted since the existence of a normal distribution is a prerequisite for applying the $t$-test. Although no normal distribution of the variables of the test samples could be assumed, most scores were distributed within the range of \pm 1 standard deviations around the samples' means. No outliers were detected. Following the usual practice, the significance level $\alpha$ was set at 0.05 .

\subsubsection{Results}

In the following the descriptive statistics and the results of the statistical analysis of the experimental hypotheses are presented.

Table 7 summarises the descriptive statistics with pre- and post-test scores of the dependent variables for groups A and B. The last two sections of Table 1 show the calculated mean, median and standard deviation of the differences between post and pre-test scores. 
Table 7. Scores of dependent variables

\begin{tabular}{llccccc}
\hline & & Y.1 & Y.2 & Y.3 & Y.4 & Y.5 \\
\hline Group A & Mean & 1.520 & 1.438 & 1.125 & 0.897 & 0.617 \\
pre-test & Median & 1.227 & 1.354 & 1.048 & 0.543 & 0.211 \\
scores & Stdev & 0.912 & 1.124 & 0.988 & 0.545 & 0.333 \\
Group A & Mean & 3.121 & 3.012 & 2.775 & 1.436 & 0.968 \\
post-test & Median & 3.329 & 2.930 & 2.623 & 1.500 & 1.013 \\
scores & Stdev & 1.567 & 1.769 & 1.877 & 0.986 & 0.955 \\
Group B & Mean & 1.499 & 1.446 & 0.897 & 0.751 & 0.555 \\
pre-test & Median & 1.312 & 1.200 & 0.888 & 0.568 & 0.243 \\
scores & Stdev & 1.081 & 1.007 & 0.769 & 0.521 & 0.419 \\
Group B & Mean & 2.211 & 2.893 & 1.989 & 1.246 & 0.797 \\
post-test & Median & 2.222 & 2.700 & 2.001 & 1.622 & 1.083 \\
scores & Stdev & 1.832 & 1.921 & 1.512 & 1.072 & 0.745 \\
Group A & Mean & 1.601 & 1.574 & 1.650 & 1.346 & 0.351 \\
Difference & Median & 2.102 & 1.576 & 1.575 & 0.957 & 0.802 \\
scores & Stdev & 1.502 & 1.034 & 1.025 & 1.098 & 0.622 \\
Group B & Mean & 0.712 & 1.447 & 1.092 & 0.495 & 0.242 \\
Difference & Median & 0.910 & 1.500 & 1.113 & 1.054 & 0.840 \\
scores & Stdev & 0.704 & 1.399 & 0.975 & 0.784 & 0.437 \\
\hline
\end{tabular}

Table 8 shows the results of the $H_{0,1}$ testing for each dependent variable (separately) based on a one-tailed $t$-test. Column shows the Cohen's $d$ effect size, column three the degrees of freedom (DOF), column four the $t$-values, column five the critical values when $\alpha=0.05$ (Crit. $t_{0.90}$ ) and column six the associated $p$-value. Columns four and six show that group A achieved statistically significant for all variables. Also, the first two variables indicate high practical significance whereas Y.3 is in the boundary region of moderate/ high practical significance and Y.4 and Y.5 show moderate practical significance. All variables indicate positive learning effectiveness.

Table 8. Results for post-test versus pre-test for group A

\begin{tabular}{cccccc}
\hline Variable & $d$ & DOF & $t$-value & Crit. $t_{0.90}$ & $p$-value \\
\hline Y.1 & 1.249 & 25 & 3.123 & 1.316 & 0.0022 \\
Y.2 & 1.062 & 25 & 2.655 & 1.316 & 0.0068 \\
Y.3 & 1.100 & 25 & 2.750 & 1.316 & 0.0055 \\
Y.4 & 0.677 & 25 & 1.692 & 1.316 & 0.0515 \\
Y.5 & 0.491 & 25 & 1.227 & 1.316 & 0.1156
\end{tabular}

Using the same structure as in Table 8, Table 9 displays the results for control group B. The case for positive learning effectiveness is less obvious when compared to the results of Table 8. The variables Y.2 and Y.3 have $p$-values less than 0.05 , which is a standard indication of statistically significant results for these two variables and they also have Cohen's $d$ values indicating moderate to high practical significance. The results for variables Y.1, Y.4 and Y.5 indicate low to moderate practical significance.

Table 9. Results for post-test versus pre-test for group B

\begin{tabular}{cccccc}
\hline Variable & $d$ & DOF & $t$-value & Crit. $t_{0.90}$ & $p$-value \\
\hline Y.1 & 0.473 & 24 & 1.134 & 1.318 & 0.1340 \\
Y.2 & 0.943 & 24 & 2.261 & 1.318 & 0.0166 \\
Y.3 & 0.910 & 24 & 2.182 & 1.318 & 0.0196 \\
Y.4 & 0.587 & 24 & 1.408 & 1.318 & 0.0860 \\
Y.5 & 0.400 & 24 & 0.959 & 1.318 & 0.1736 \\
\hline
\end{tabular}

The results when testing $H_{0,2 a}$ are shown in Table 10. Results for the variables Y.1 and Y.4 show both statistically and practical significance while the result for Y.3 shows moderate practical significance. The variable Y.5 has a result 
showing a small practical significance and Y.2 suggests low practical significance. Overall it can be argued however, that these results show difference in relative learning effectiveness between group A and group B and so $H_{0,2 a}$ can be rejected.

Table 10. Results for performance improvement, group A versus group B

\begin{tabular}{cccccc}
\hline Variable & $d$ & DOF & $t$-value & Crit. $t_{0.90}$ & $p$-value \\
\hline Y.1 & 0.757 & 50 & 2.650 & 1.299 & 0.0070 \\
Y.2 & 0.103 & 50 & 0.361 & 1.299 & 0.3606 \\
Y.3 & 0.558 & 50 & 1.953 & 1.299 & 0.0313 \\
Y.4 & 0.892 & 50 & 3.122 & 1.299 & 0.0023 \\
Y.5 & 0.202 & 50 & 0.707 & 1.299 & 0.2432
\end{tabular}

Table 11 shows the results of the testing of $H_{0,2 b}$ which examines the absolute learning of both groups. The variables Y.1 and Y.3 indicate moderate to large practical significance whereas Y.3 and Y.5 indicate small to moderate practical significance. The dependent variable Y.2 supports the direction of the expected positive learning effectiveness but with a very low practical significance. Generally it can be said that the experimental hypothesis holds regarding absolute learning effectiveness and $H_{0,2 b}$ can be rejected.

Table 11. Results for post-test improvement, group A versus group B

\begin{tabular}{cccccc}
\hline Variable & $d$ & DOF & $t$-value & Crit. $t_{0.90}$ & $p$-value \\
\hline Y.1 & 0.534 & 50 & 1.868 & 1.299 & 0.0370 \\
Y.2 & 0.064 & 50 & 0.225 & 1.299 & 0.4119 \\
Y.3 & 0.461 & 50 & 1.614 & 1.299 & 0.0598 \\
Y.4 & 0.185 & 50 & 0.646 & 1.299 & 0.2622 \\
Y.5 & 0.200 & 50 & 0.700 & 1.299 & 0.2453 \\
\hline
\end{tabular}

\subsubsection{Discussion}

Based on the results presented in the previous sub-section and additional observations, the outcome of the experiment is now interpreted. As reported the change from pre- to post-test scores for the experimental group A confirmed a statistically significant positive impact on learning effectiveness and to some extent practical significance on learning effectiveness. The results did show a trend of giving less significant effectiveness as the questions increasingly required more critical thinking to get an appropriate answer. The improvement in results for group B was not as impressive when considering positive learning effectiveness. However there was an improvement in learning between pre- and post-tests.

Testing the performance of relative learning between groups A and B showed that all variables showed a statistical significant improvement with the advent of critical thinking components. The results are mixed though, in that for variable Y.2 and Y.5 there was only a small impact of relative learning effectiveness. A similar result was found for the absolute learning effectiveness.

Some potential threats to the validity of the above results have been identified. Concerning internal validity a selection effect was avoided to some extent by equalising the ability of the groups using the results of a closely related module on thermodynamics. The experimental design (i.e. introducing the experiment to students directly before the experiment) avoided students dropping out. The maturation effect caused by familiarisation and maturing was avoided by not informing students ahead of time that there would be a post-test. However, the internal validity might have been limited by the different interaction density between groups A and B (instrumentation effect). Concerning the external validity it can be expected that the results of the study are to some degree representative for the category of students found here. Students with different educational backgrounds, fields of study and socio-economic contexts may lead to different results. The exploratory character of the research presented here needs to be recognised and further investigations might lead to more generalised results.

\subsection{Questionnaire Results of Initial Critical Thinking Course}

An online questionnaire as summarized in Table 13 was used as the basis for evaluating the initial critical thinking course and consisted of questions to which a five-point rating scale was attached. The ratings have an ordinal rank (i.e. 
from low to high) and Table 12 shows the weightings from the student responses. From a total cohort of 171 students some 90-94 $(n)$ responded.

Table 12. Weighting factors in percentages used for ordinal rating scales

\begin{tabular}{ll}
\hline Rating & Ordinal Weighting (\%) \\
\hline A & 100 \\
B & 75 \\
C & 50 \\
D & 25 \\
E & 0 \\
\hline
\end{tabular}

The results are summarized in Table 13. It can be seen that students tended to find the concepts of the course fairly easy. This was a very important finding in that the students must understand what critical thinking is in order to apply critical thinking to challenging problems without worrying much as to how to apply it. It is obvious that assignments could be improved, probably by more grading of problems so that the learning curve employing critical thinking is lessened.

Table 13. Number of student responses, $n$, and weighted scores for the questions

\begin{tabular}{|c|c|c|c|c|c|}
\hline $\begin{array}{l}\text { Characteristics of } \\
\text { course }\end{array}$ & $\begin{array}{l}\text { A } \\
\text { weighting } \\
\text { extreme }\end{array}$ & $\begin{array}{l}\mathrm{E} \\
\text { weighting extreme }\end{array}$ & $n$ & $\begin{array}{l}\text { Score } \\
(\text { Mean) } \\
(\%)\end{array}$ & $\begin{array}{l}\text { Standard } \\
\text { Deviation }\end{array}$ \\
\hline $\begin{array}{l}\text { 1. Rate the difficulty } \\
\text { of the concepts } \\
\text { covered in the course }\end{array}$ & Very easy & Very difficult & 93 & 76 & 5.6 \\
\hline $\begin{array}{l}\text { 2. Rate the workload } \\
\text { to complete this } \\
\text { course }\end{array}$ & Very little & Very heavy & 90 & 63 & 4.8 \\
\hline $\begin{array}{l}\text { 3. To what extent did } \\
\text { the assignments } \\
\text { contribute to a better } \\
\text { understanding of the } \\
\text { concepts? }\end{array}$ & Helped a lot & Totally useless & 93 & 57 & 7.2 \\
\hline $\begin{array}{l}\text { 4. How well did the } \\
\text { assessments reflect the } \\
\text { course material? }\end{array}$ & Very closely & Not at all & 94 & 64 & 6.4 \\
\hline $\begin{array}{l}\text { 5. What was your } \\
\text { overall appraisal of } \\
\text { this course? }\end{array}$ & Excellent & Poor & 94 & 72 & 4.6 \\
\hline $\begin{array}{l}\text { 6. What was your } \\
\text { attendance rate? }\end{array}$ & All classes & No classes & 93 & 86 & 3.5 \\
\hline
\end{tabular}

\subsection{Discussion with Selected Students}

Twenty students were selected at random to give preliminary feedback on the impact of the above work so far in the form of a group discussion. As already alluded to, most of these students already thought of themselves as critical thinkers before the year started. This could be a widespread self-delusion, and it is clear work needs to be done to find out how true this self-opinion is. If it is untrue, then a process of changing attitudes and intellectual disposition, and, engendering a willingness on the part of the students to dedicate themselves more to thinking critically must ensue.

The majority of students thought the initial course on critical thinking quite cumbersome and unnecessarily long. They thought that a more condensed message, more dedicated to explaining and reinforcing the 'Essential Intellectual Standards', may be more effective. They explained that at the end of the day they need a brief list of rules and processes to go by, to give a manageable framework to work within. 
Certainly the students recognised that critical thinking is a process and with practice and the correct attitude they would become much better at it. They all stated that more critical thinking within each engineering module they took must be increased.

\subsection{Discussion with Selected Faculty}

Interviews were also conducted with twelve faculty, i.e. three from each of the engineering disciplines, mechanical, chemical, electrical \& electronics and civil. The faculty were randomly chosen from a total of 62 faculty and the survey was in the form of individual discussions. The following are a summary of these discussions.

The chosen faculty as a group were quite enthusiastic about the inclusion of critical thinking as an integral part of their respective courses but were not enthusiastic about testing critical thinking as a separate entity. There was general agreement that critical thinking should not be separated from the course material, as otherwise valuable time would be taken away from teaching and learning course content. Some of the staff expressed the view that a series of short courses must be implemented to increase their skills in including critical thinking both in the delivery of the course and in how best to assess it. They thought there was not enough uniformity between staff, especially in the method of assessment. They also generally thought that for assignments and projects it was relativity easy to include critical thinking and most felt comfortable in doing so, but short-questions were difficult to assemble.

\section{Conclusions}

Methods to cultivate critical thinking within engineering education have been examined and to some extent implemented. Essentially three major innovations have taken place, the first being the establishment of an initial course to students on what critical thinking is, why it is important an engineer has such a skill and how to incorporate this skill into everyday engineering practice. The second innovation was the creation of a seminar/discussion group for faculty on integrating critical thinking into their respective engineering modules. The third innovation is the development of a method to assess critical thinking during several phases of open-ended assignments in engineering. The method is designed to track the development of critical thinking as a student progresses through the undergraduate curriculum. Student feedback so far has asked for a more streamlined initial course and has encouraged course material in each module to include opportunities for more critical thinking.

The experiment presented here evaluated the learning effectiveness of including critical learning components in the module 'Introduction to Fluid Mechanics'. The results showed a significant improvement in learning effectiveness when including the critical learning components. In future introduction of the approach emphasising critical thinking and problem-solving will be introduced from the beginning of the module.

\section{References}

Adair, D., Bakenov, Z. \& Jaeger, M. (2014). Building on a traditional chemical engineering curriculum using computational fluid dynamics. Education for Chemical Engineers, 9(3), 30-38. http://dx.doi.org/10.1016/j.ece.2014.06.001

Adair, D. \& Jaeger, M. (2013). Integrating a computer system into an engineering mathematics course. Société Européenne pour la Formation des Ingénieurs, Annual Conference, Leuven, Belgium, 16-20 ${ }^{\text {th }}$ September, 2013.

American Association for the Advancement of Science (1989). Science for all Americans. Oxford University Press, New York.

Aretz, A. J., Bolen, M. T. \& Devereux, K. E. (1997). Critical thinking assessment of college students. Journal of College Reading and Learning, 28, 12-23. http://dx.doi.org/10.1080/10790195.1997.10850050

Aviles, C. B. (1999). Understanding and testing for 'Critical Thinking' with Bloom's Taxonomy of Educational Objectives. Washington (DC): ERIC Clearinghouse, Report No. SO032219.

Baillie, C. (2012). Critical theory of technological development - course outline. University of Western Australia.

Baillie, C. (2013). Reimagining engineering and its education. Société Européenne pour la Formation des Ingénieurs, Annual Conference, Leuven, Belgium, 16-20 ${ }^{\text {th }}$ September.

Beins, B. C. (2009). Research Methods. Pearson Education, Boston, MA.

Beyer, B. K. (1984). Improving thinking skills - defining the problem. Phi Delta Kappan, 65, 486-490.

Bissell, A. N., \& Lemons, P. R. (2006). A new method for assessing critical thinking in the classroom. BioScience, 56(1), 66-72. http://dx.doi.org/10.1641/0006-3568(2006)056[0066:ANMFAC]2.0.CO;2

Bloom, B. S. ed. (1956). Taxonomy of educational objectives: The classification of educational goals. New York, 
McKay.

Bloom, B. S. (1984). Taxonomy of educational objectives. Handbook 1: Cognitive Domain. New York, Addison Wesley.

Bloom, B. S. Karthwohl, D. R. \& Massia, B. B. (1984). Taxonomy of educational objectives. Handbook 2: Affective Domain, New York, Adison Wesley.

Brookfield, S. D. (2012). Teaching for critical thinking: Tools and techniques to help students question their assumptions. Jossey-Bass, San Franscisco, CA.

Bruno, B. \& Anderson, A. (2005). Using objective-driven heat transfer lab experiences to simultaneously teach critical thinking skills and technical content. in Proc. ASME Int. Mechanical Engineering Cong. Expo., Orlando, FL. http://dx.doi.org/10.1115/imece2005-82689

Cloete, A. (2001). Solving problems or problem solving: What are we teaching our students? American Society for Engineering Education Conference and Exhibition, Albuquerque, NM, 24-27 June.

Cooney, E., Alfrey, K., \& Owens, S. (2008). Critical thinking in engineering and technology education: A review. American Society for Engineering Education Annual Conference and Exhibition, Pittsburgh, PA, 22-25 ${ }^{\text {th }}$ June.

Cromwell, L. S. (1992). Assessing critical thinking. New Directions for Community Colleges, 77, 37-50. http://dx.doi.org/10.1002/cc.36819927705

Dewey, J. (1910). How we think. Lexington, Mass:Heath. http://dx.doi.org/10.1037/10903-000

Ebert-May, D., Batzli, J. \& Lim, H. (2003). Disciplinary research strategies for assessment of learning. BioScience, 53, 1221-1228. http://dx.doi.org/10.1641/0006-3568(2003)053[1221:DRSFAO]2.0.CO;2

Facione, P. A. (2015) Critical thinking: What it is and why it counts. Insight Assessment Update.

Facione, P. A., Facione, N. C., \& Giancarlo, C. A. (2000). The disposition toward critical thinking: Its character, measurement, and relationship to critical thinking skill, Informal Logic, 20, 61-84.

Felder, R. M. (1984). Does engineering education have anything to do with either one? Reynolds Industries Award Distinguished Lecture Series, North Carolina State University, Oct.

Felder, R. M. (1987). On creating creative engineers. Engineering Education, 77(4), 222-227.

Felder, R. M., Woods, D. R., Stice, J. E. \& Rugarcia, A. (2000). The future of engineering education II Teaching methods that work. Chem. Eng. Education, 34(1), 26-39.

Fisher, A. \& Scriven, M. (1997). Critical thinking: Its definition and assessment. Point Reyes (CA), Edgepress.

Glaser, E. M. (1941). An experiment in the development of critical thinking. AMS Press, New York, NY.

Gurmen, N. M., Lucas, J. J., Malmgren, R. D. \& Folger, H. S. (2003). Improving critical thinking and creative problem solving skills by interactive troubleshooting. in Proc. $108^{\text {th }}$ ASEE Ann. Conf., Nashville, TN.

Lombardo, S. J. (2004). Using small blocks of time for active learning and critical thinking. Chem. Eng. Educ., 38(2), 150-153.

Lunt, B. M. \& Helps, R. G. (2001). Problem solving in engineering technology: Creativity, estimation and critical thinking are essential skills. in Proc, $108^{\text {th }}$ ASEE Ann. Conf., Albuquerque, NM.

Middendorf, J. \& Pace, D. (2004). Decoding the disciplines: A model for helping students learn disciplinary ways of thinking. New Directions for Teaching and Learning, 98, 1-12. http://dx.doi.org/10.1002/tl.142

Miller, R. L. \& Olds, B. (1994). Encouraging critical thinking in an interactive chemical engineering environment. in Proc. $24^{\text {th }}$ Ann. Frontiers Education Conf., San Jose, CA. http://dx.doi.org/10.1109/fie.1994.580590

Mina, M., Omidvar, I. \& Knott, K. (2003). Learning to think critically to solve engineering problems: Revisiting John Dewey's ideas for evaluating engineering education. in Proc. $110^{\text {th }}$ ASEE Ann. Conf., Nashville, TN.

Mourtos, N. J., Okamoto, N. D. \& Rhee, J. (2004). Open-ended problem-solving skills in thermal fluids engineering. Global J. of Engng. Educ., 8(2), 189-199.

National Academy of Sciences - National Research Council (2003). BIO 2010: Transforming undergraduate education for future research biologists. National Academies Press, Washington (DC).

Nelson, S. (2001). Impact of technology on individuals and society: A critical thinking and lifelong learning class for engineering students. in Proc. $31^{\text {st }}$ Ann. Frontiers Education Conf., Reno, NV. 
http://dx.doi.org/10.1109/fie.2001.963983

Niewoehner, R. J. (2006). A critical thinking model for engineering. $2^{\text {nd }}$ International CDIO Conference, Linköping, Sweden, 13-14 $4^{\text {th }}$ June, 2006.

O’Shea, J., Baillie, C. \& Armstrong, R. (2012). Developing critical thinking skills and an understanding of social justice in engineering education. AAEE 2012 Conference, Melbourne, Australia, $3^{\text {rd }}-5^{\text {th }}$ December.

Papadopoulos, C., Rahman, A. \& Bostwick, J. (2006). Assessing critical thinking in mechanics in engineering education. in Proc. $113^{\text {th }}$ ASEE Ann. Conf., Chicago, IL.

Paul, R. W., Elder, L. \& Bartell, T. (1997). California teacher preparation for instruction in critical thinking: Research findings and policy recommendations. Foundations for Critical Thinking, Santa Rosa (CA).

Paul, R. W. \& Elder, L. (2002). Critical thinking: Tools for taking charge of your professional and personal life. Prentice-Hall, Upper Saddle, NJ.

Pfahl, D., Laitenberger, O., Ruhe, G., Dorsch, J. \& Krivobokova, T. (2004). Evaluating the learning effectiveness of using simulations in software project management education: results from a twice replicated experiment. Information and Software Technology, 46, 127-147. http://dx.doi.org/10.1016/S0950-5849(03)00115-0

Porter, A. C. (2002). Measuring the content of instruction: Uses in research and practice, Educational Researcher, 31, 3-14. http://dx.doi.org/10.3102/0013189X031007003

Potts, B. (1994). Strategies for teaching critical thinking in education. ERIC Clearinghouse, Report No. ED385606, Washington (DC).

Purves, C. A. (2009). Factors that influence the development of critical thinking skills in associate degree nursing students. PhD Dissertation, University of Georgia, Athens, Georgia.

Resnick, L. B. (1987). Education and learning to think. National Academy Press, Washington (DC).

Seymour, E. (2002). Tracking the processes of change in US undergraduate education in science, mathematics, engineering and technology. Science Education, 86(1), 79-105. http://dx.doi.org/10.1002/sce.1044

Swaile, B. H. \& Kreppel, M. C. (2001). Building critical thinking, teamwork and communication skills through professional ethics in engineering and chemical technology. in Proc. $108^{\text {th }}$ ASEE Ann. Conf., Albuquerque, NM.

White, F. M. (1998). Fluid mechanics. $4^{\text {th }}$ ed. McGraw-Hill, New York, NY.

Wolverton, R. H. \& Wolverton, J. B. (2003). Implementation of ethics education throughout an engineering college. in Proc. $108^{\text {th }}$ ASEE Ann. Conf., Nashville, TN.

Woods, D. R., Hrymak, A. N., Mashall, R. R., Wood, P. E., Crowe, C. M., Hoffman, T. W., Wright, J. D., Taylor, P. A., Woodhouse, K. A. \& Bouchard, C. G. K. (1997). Developing problem-solving skills: the McMaster problem-solving program. ASEE J. of Engng Educ., http://dx.doi.org/10.1002/j.2168-9830.1997.tb00270.x

Yuretich, R. F. (2004). Encouraging critical thinking: Measuring skills in large introductory science classes. Journal of College Science Teaching, 33, 40-46. 


\section{Appendix}

The following questions were used to assess the critical thinking skills acquired by the two groups A and B during the teaching phase of the 'Introduction to Fluid Mechanics' module. There were five questions selected from White, 1998 and Mourtos et al., 2004. The questions are graded so that critical thinking is increasingly used to get an appropriate answer, as the questions move from relatively familiar topics to topics not considered directly during the course and where the statement may deliberately appear ambiguous to students.

Y.1 The Stokes-Oseen formula for drag force $F$ on a sphere of diameter $D$ in a fluid stream of low velocity $V$, density $\rho$ and viscosity $\mu$ is

$$
F=3 \pi \mu D V+9 \pi \rho V^{2} D^{2} / 16
$$

For small particles at low velocities, the first term in the above equation is dominant; hence, $F \approx K V$ where $K$ is a constant. Suppose a particle of mass $m$ is constrained to move horizontally from the initial position $x=0$ with initial velocity $V_{0}$. Show

(a) that its velocity will decrease exponentially with time.

(b) that it will stop after travelling a distance $x=m V_{0} / K$.

Y.2 Water enters the bottom of the cone on the figure below at a uniformly increasing average velocity $V=K t$. If $d$ is very small, derive an analytic formula for the water surface rise $h(t)$ for the condition $h=0$ at $t=0$. Assume incompressible flow.

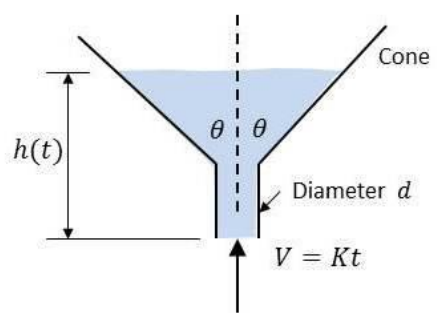

Y.3 The device on the figure below is called a rotating disk viscometer. Suppose that $R=5 \mathrm{~cm}$ and $h=1 \mathrm{~mm}$. If the torque required to rotate the disk at $900 \mathrm{r} / \mathrm{min}$ is $0.537 \mathrm{Nm}$, what is the viscosity of the fluid? If the uncertainty in each parameter $(M, R, h, \Omega)$ is \pm 1 percent, what is the overall uncertainty in the viscosity?

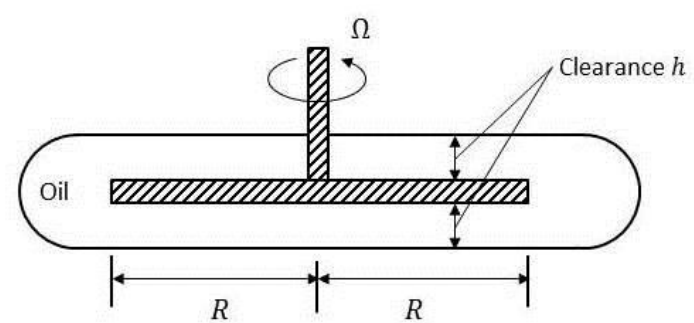

Y.4 The party is over and it is raining hard. Your car is parked several streets away. The way to your car is open, exposed to the rain. You are wearing your new, designer clothes. You just got the first monthly statement and it hurts. You want to make sure you soak them as little as possible. You have no umbrella. You are getting ready to run as hard as you can when all of a sudden, you start doubting whether this is the best way to save your clothes. Should you walk instead? The decision is too important to leave to chance. Besides, you are an engineer. You walk back into the building, pull out a pencil and piece of paper and start looking for the right answer.

Y. 5 Consider an aircraft in flight. Which aerodynamic surface is working harder to generate lift: the wing or the horizontal stabilizer? Why? 